Supporting Information Available:

\title{
Excited state enantiodifferentiating interactions between a chiral benzophenone derivative and nucleosides
}

Virginie Lhiaubet-Vallet, Susana Encinas, Miguel A. Miranda*

\section{Table of contents:}

S1: This page

S2: HPLC and ${ }^{1} \mathrm{H}-\mathrm{NMR}$ data of UVA-irradiation of benzophenone in the presence of Thd (ratio 2/1).

S3: ${ }^{1} \mathrm{H}-\mathrm{NMR}$ spectra of the two major oxetanes obtained upon UVA-irradiation of benzophenone in the presence of thymidine.

S4: HPLC traces of UVA-irradiation of (S)-KP in the presence of thymidine $(2 / 1$ and $1 / 3$ ratio).

S5: ${ }^{1} \mathrm{H}-\mathrm{NMR}$ spectra of UVA-irradiation of (S)-ketoprofen in the presence of thymidine (ratio $2 / 1$ and $1 / 3$ ).

S6: ${ }^{1} \mathrm{H}-\mathrm{NMR}$ spectrum of the major regioisomers separated after irradiation of (S)-ketoprofen in the presence of thymidine (ratio 2/1).

S7: ${ }^{1} \mathrm{H}-\mathrm{NMR}$ spectra of UVA-irradiation of (R)-ketoprofen in the presence of thymidine (ratio 2/1).

S8: Kinetics of the degradation of Thd upon UVA-irradiation in the presence of (R)- or (S)-KP (ratio KP/Thd : 2/1). 


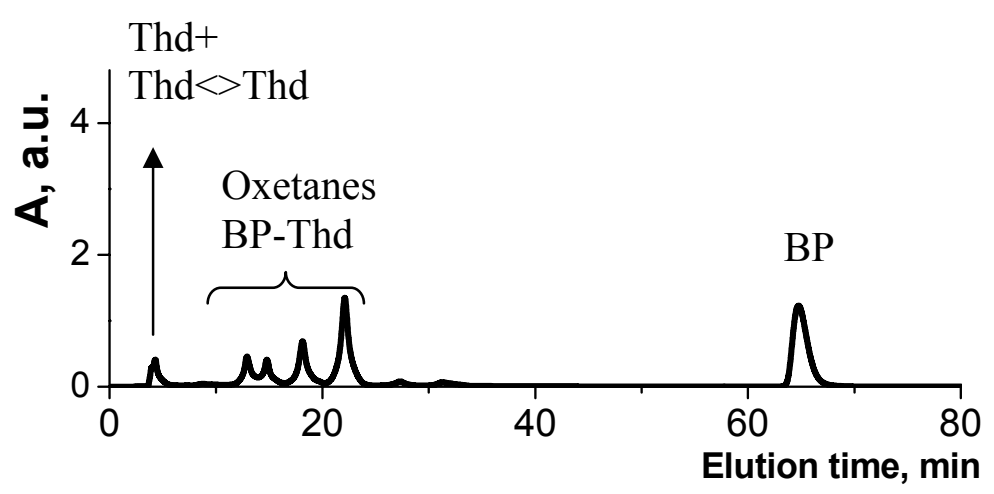

Figure S2a : HPLC trace (detection at $210 \mathrm{~nm}$ ) of UVA-irradiation of benzophenone (BP) in the presence of thymidine (ratio 2/1). Eluent: Methanol/ Water / Trifluoroacetic acid, 50/49.9/0.1

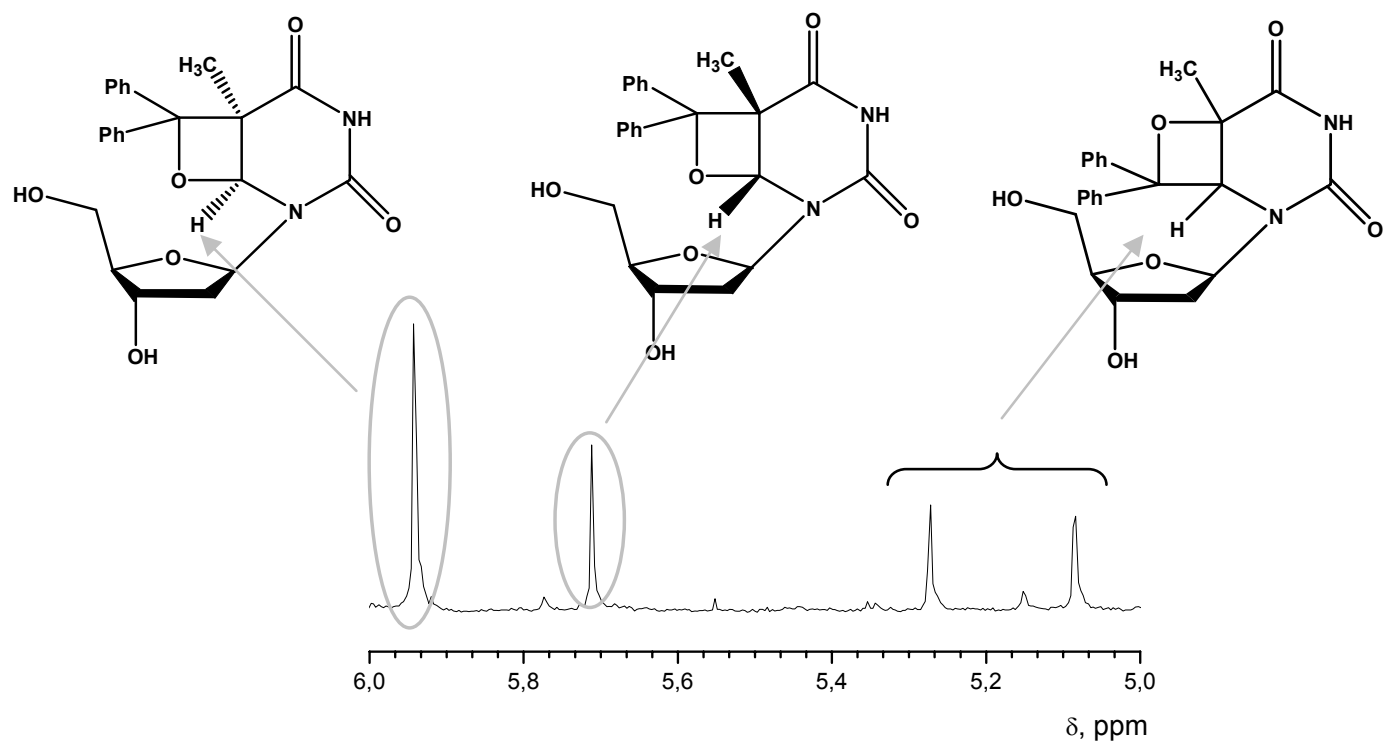

Figure S2b : ${ }^{1} \mathrm{H}-\mathrm{NMR}$ spectrum in $\mathrm{CD}_{3} \mathrm{OD}$ (6.0-5.0 ppm region) of UVA-irradiation of benzophenone in the presence of thymidine (ratio 2/1). 

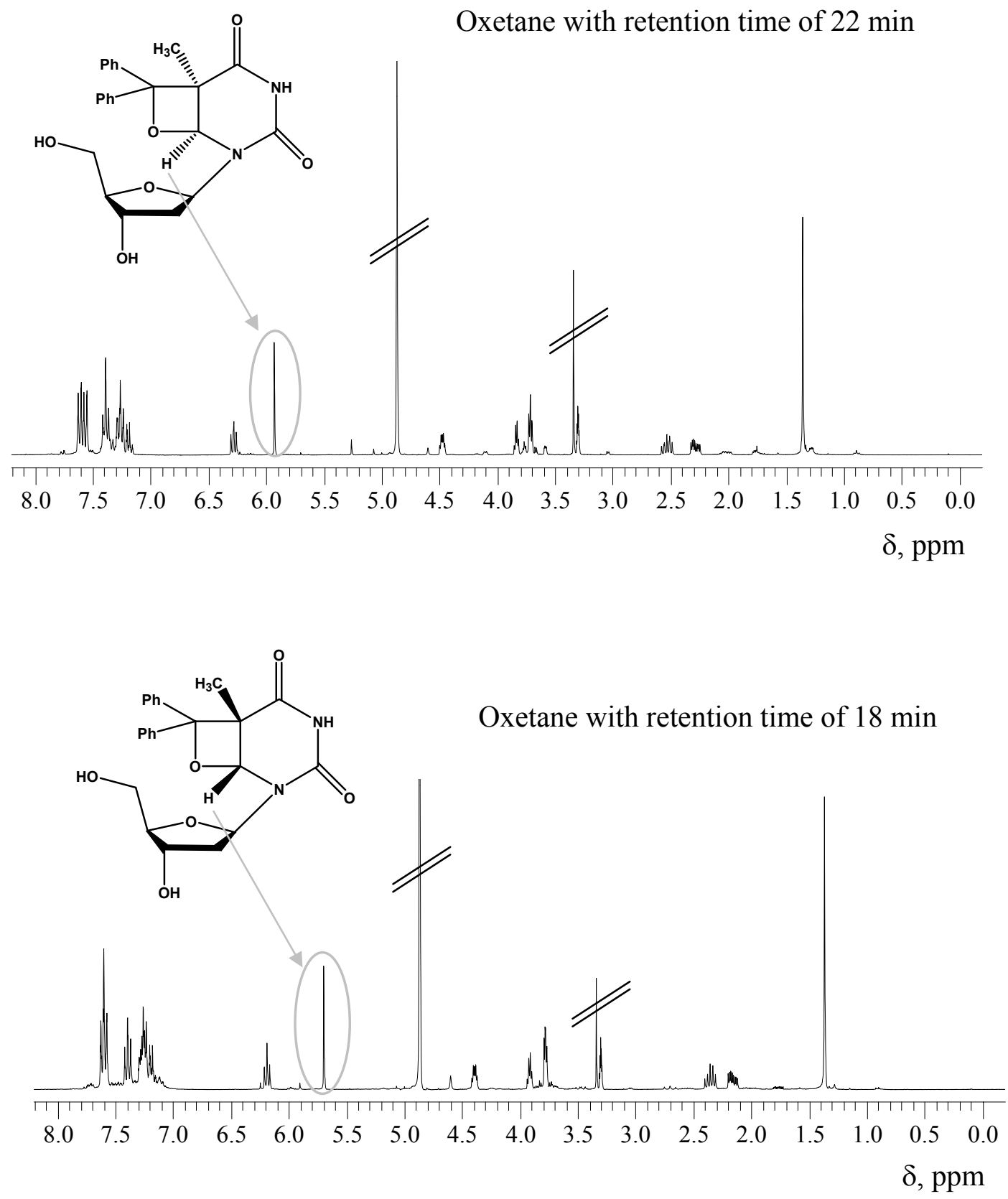

Figure S3 : ${ }^{1} \mathrm{H}-\mathrm{NMR}$ spectra in $\mathrm{CD}_{3} \mathrm{OD}$ of the two major oxetanes obtained upon UVA-irradiation of benzophenone in the presence of thymidine. 

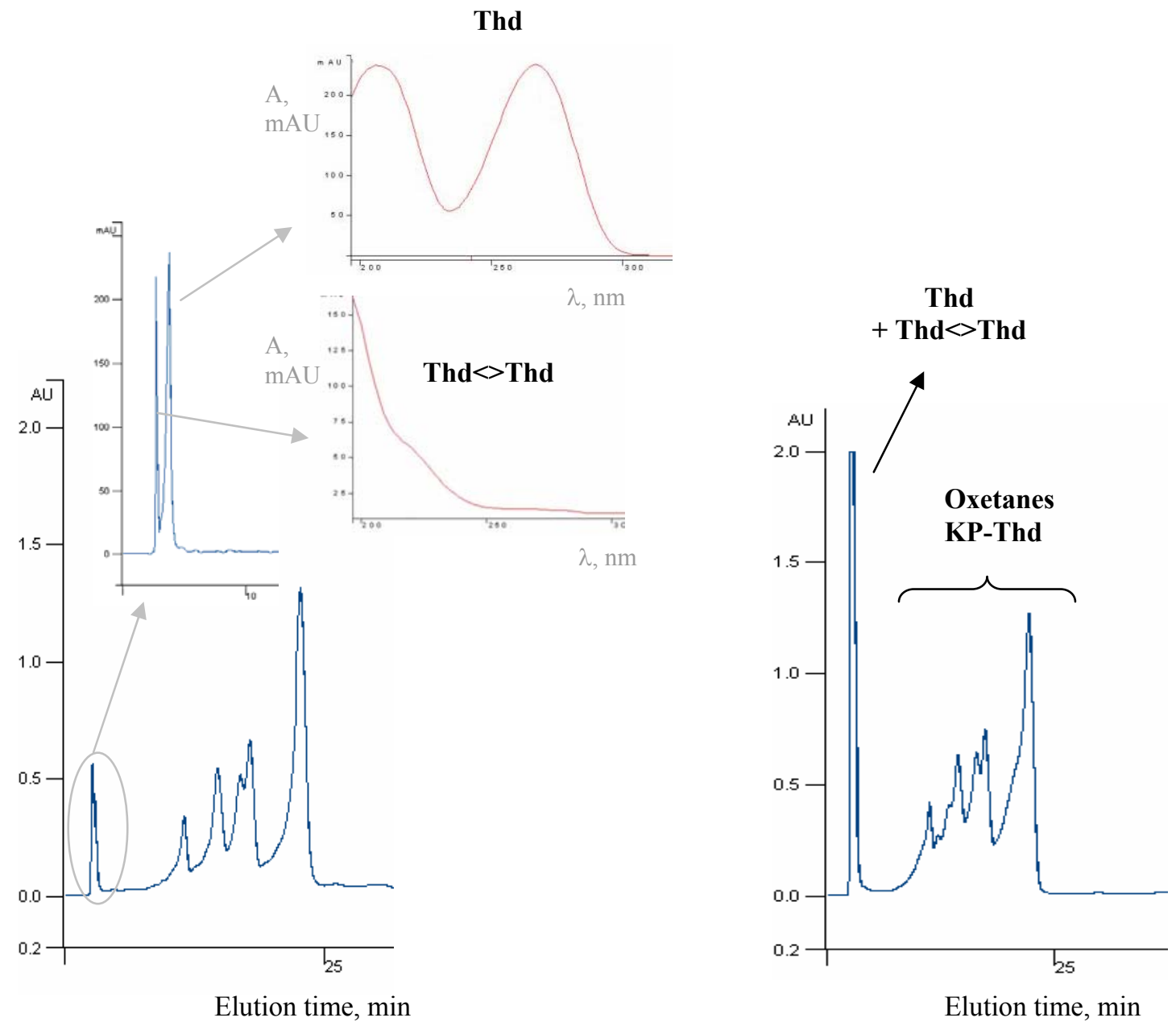

Figure S4 : HPLC traces (detection at $210 \mathrm{~nm}$ ) of UVA-irradiation of (S)-KP in the presence of thymidine (left: $2 / 1$ ratio; right 1/3 ratio).

Eluent: Methanol/ Water / Trifluoroacetic acid, 50/49.9/0.1

(Inset: Methanol/ Water / Trifluoroacetic acid, 30/69.9/0.1) 


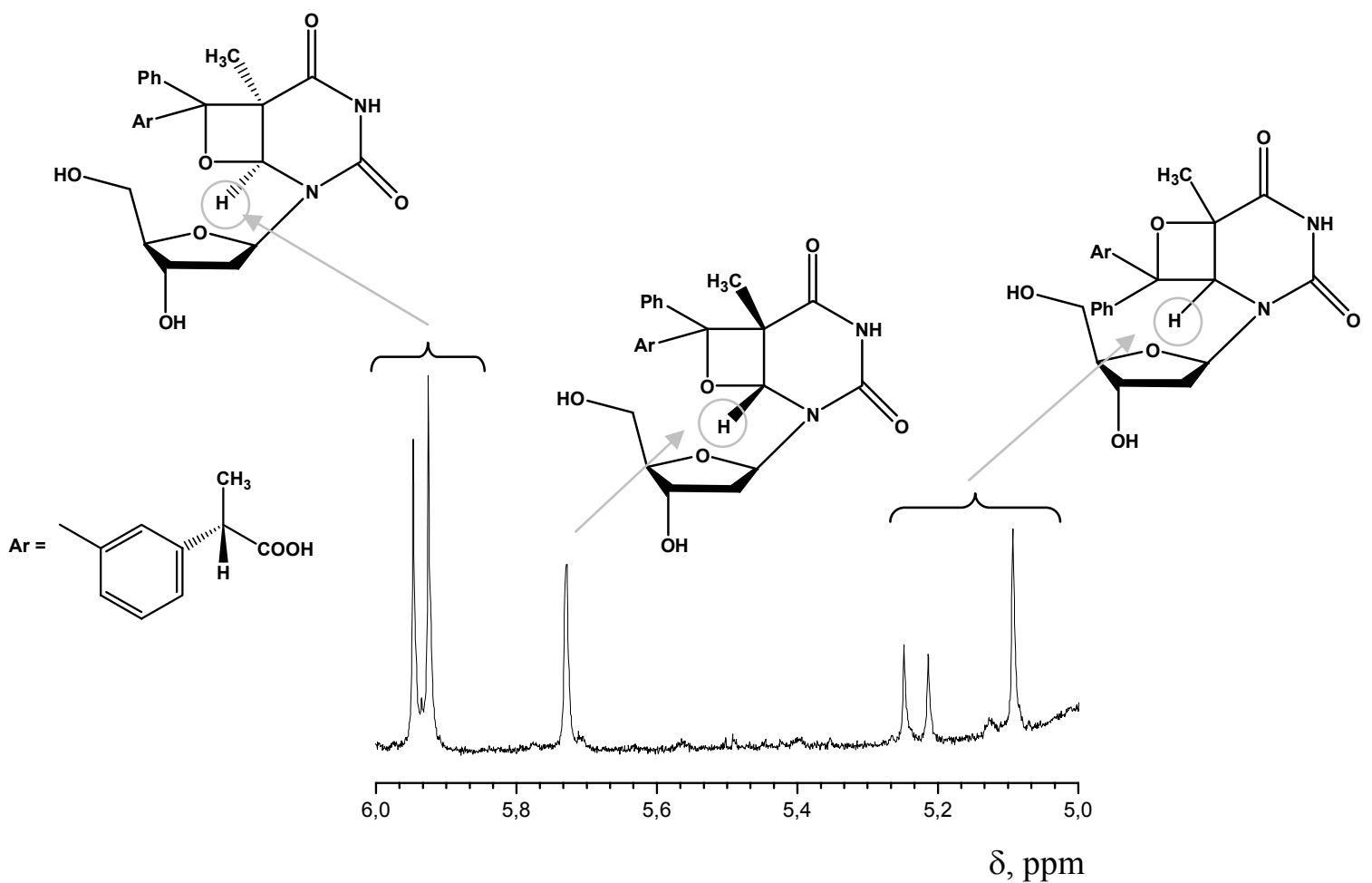

Figure S5a : ${ }^{1} \mathrm{H}-\mathrm{NMR}$ spectrum in $\mathrm{CD}_{3} \mathrm{OD}$ (6.0-5.0 ppm region) of UVA-irradiation of (S)-ketoprofen in the presence of thymidine (ratio 2/1).

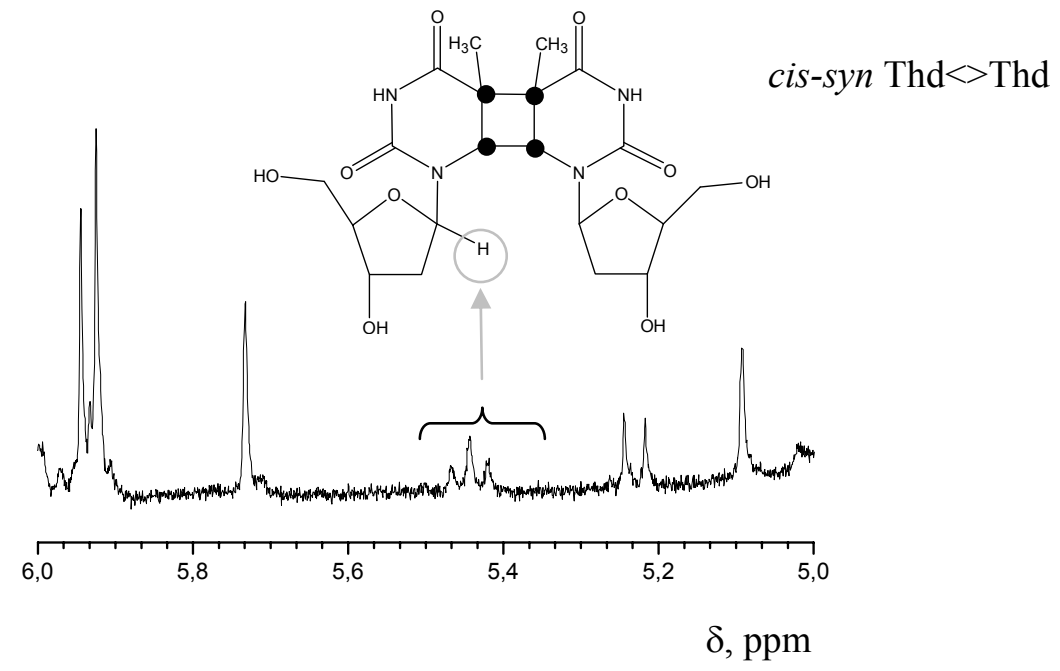

Figure S5b : ${ }^{1} \mathrm{H}-\mathrm{NMR}$ spectrum in $\mathrm{CD}_{3} \mathrm{OD}(6,0-5,0 \mathrm{ppm}$ region) of UVA-irradiation of (S)-ketoprofen in the presence of thymidine (ratio 1/3). 


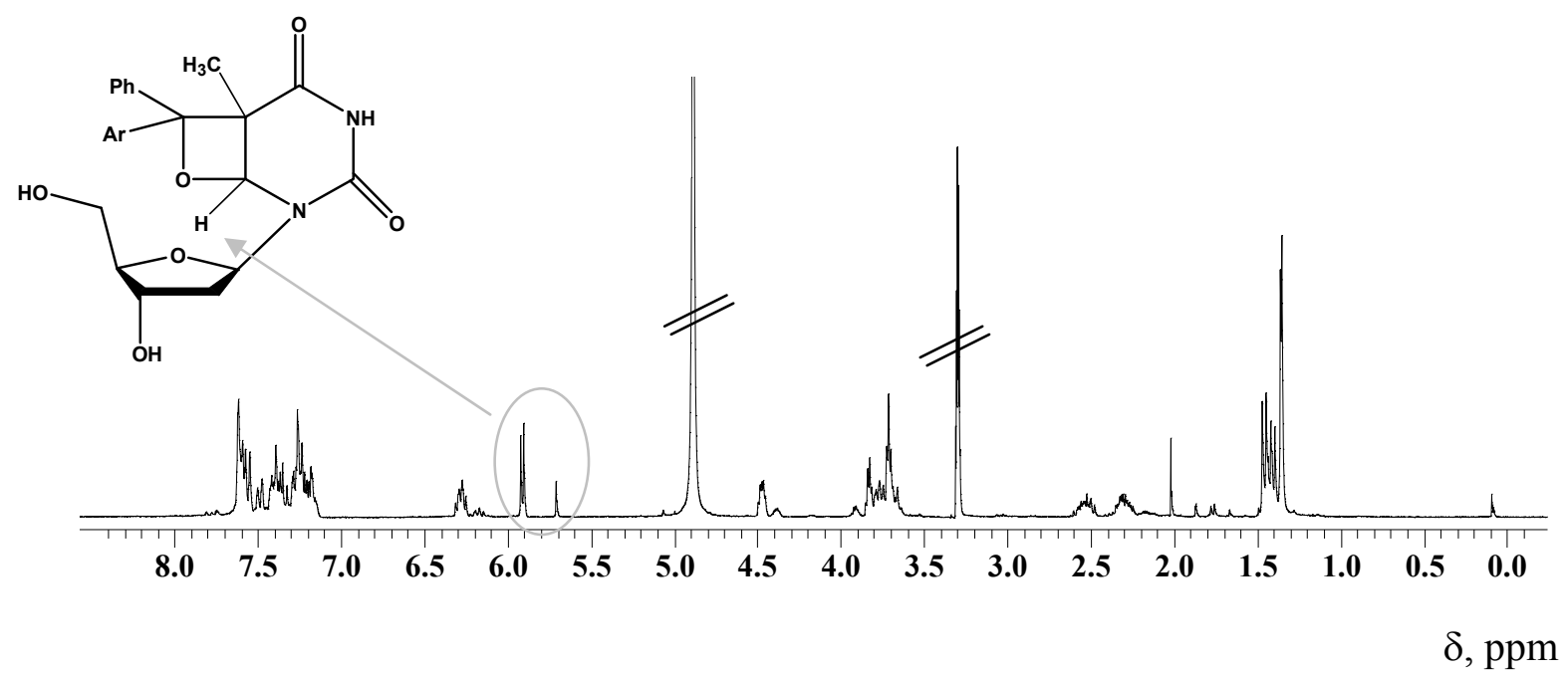

Figure S6 : ${ }^{1} \mathrm{H}-\mathrm{NMR}$ spectrum in $\mathrm{CD}_{3} \mathrm{OD}$ of the major regioisomers separated after irradiation of (S)-ketoprofen in the presence of thymidine (ratio 2/1). 


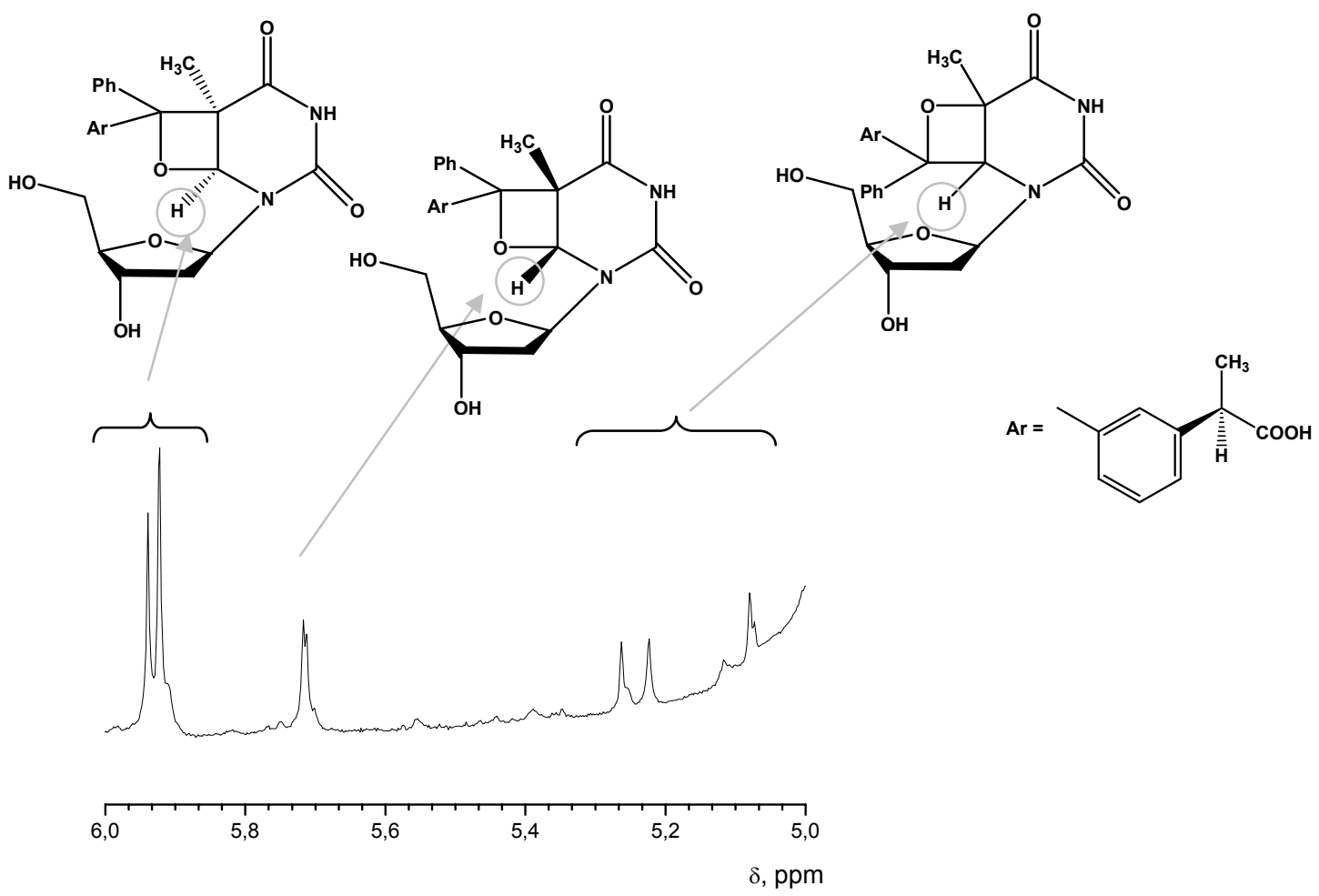

Figure S7 : ${ }^{1} \mathrm{H}-\mathrm{NMR}$ spectrum in $\mathrm{CD}_{3} \mathrm{OD}$ (6.0-5.0 ppm region) of UVA-irradiation of (R)-ketoprofen in the presence of thymidine (ratio 2/1). 


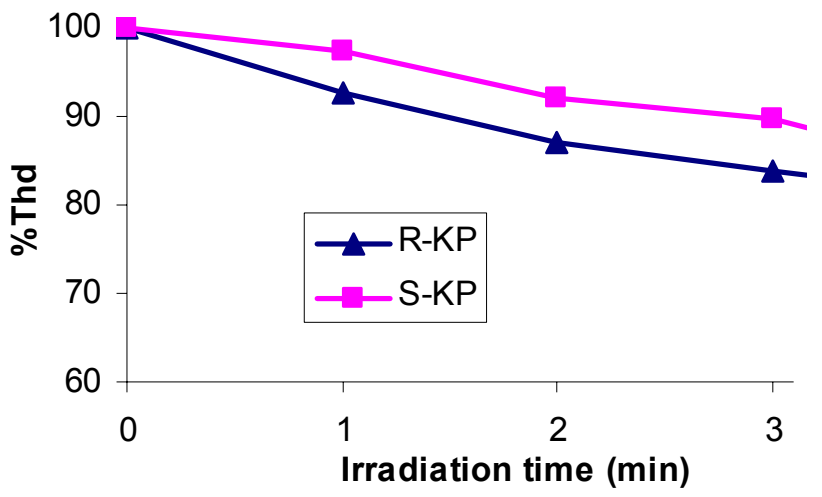

Figure S8 : Kinetics of the degradation of Thd upon UVA-irradiation in the presence of $(\mathrm{R})-$ or $(\mathrm{S})-\mathrm{KP}$ (ratio KP/Thd : 2/1). 